\title{
Effects of an Adapted Physical Activity Program on Physical Fitness of Adults with Intellectual Disabilities
}

\author{
Katerina Asonitou, Thomas Mpampoulis, Helen Irakleous-Paleologou, Dimitra Koutsouki
}

Laboratory of Adapted Physical Activity, Developmental and Physical Disabilities, School of Physical Education and Sport Science, National \& Kapodistrian University of Athens, Athens, Greece

Email: kasonitou@phed.uoa.gr

How to cite this paper: Asonitou, K., Mpampoulis, T., Irakleous-Paleologou, H., \& Koutsouki, D. (2018). Effects of an Adapted Physical Activity Program on Physical Fitness of Adults with Intellectual Disabilities. Advances in Physical Education, 8, 321-336.

https://doi.org/10.4236/ape.2018.83028

Received: July 30, 2018

Accepted: August 25, 2018

Published: August 28, 2018

Copyright $\odot 2018$ by authors and Scientific Research Publishing Inc. This work is licensed under the Creative Commons Attribution International License (CC BY 4.0).

http://creativecommons.org/licenses/by/4.0/

cc) (i) Open Access

\begin{abstract}
People with Intellectual Disability (ID) constitute a vulnerable social group, making their physical health improvement a primary concern to all involved with their care. We constructed and evaluated a physical training intervention conducted twice per week for 4 consecutive months, consisting of activities and games to improve muscle strength, speed, balance and flexibility. Participants were 38 adults with intellectual disabilities divided into two groups: 1) the intervention group $(\mathrm{n}=19)$ who participated in exercise training; and 2) the control group $(n=19)$ who engaged in no exercise training. All participants were evaluated on seven physical fitness tests, before and after implementation of the four-month training program. The present study was designed to improve certain aspects of fitness among adults with mild ID. The results showed that the mean anthropometric characteristics suggestive of better health and all physical fitness measures for the intervention group were reflected positive improvements at post-tests. The study showed that a structural physical exercise program can improve physical fitness of adults with mild intellectual disabilities, especially muscle strength and endurance, balance, flexibility, speed and cardio-respiratory endurance, in order to promote a more active and healthier way of life.
\end{abstract}

\section{Keywords}

Intellectual Disability (ID), Exercise Intervention Program, Adapted Physical Activity, Eurofit Physical Fitness Test Battery, Quality of Life

\section{Introduction}

Individuals with intellectual disability (ID) often show problems in many dif- 
ferent domains of their everyday life. Besides the difficulties they face in cognitive, adaptive and social behavior, they often show low levels of physical fitness throughout life (Pitetti \& Boneh 1995; Skowronski et al., 2009; Van de Vliet et al., 2006). Many researchers have found that adults with ID show low performance on standardized assessments of physical fitness and specifically in cardiovascular endurance, body composition, muscle strength and endurance, and muscle coordination (Carmeli et al., 2008; Chanias, Reid, \& Hoover, 1998; Frey, Stanish, \& Temple, 2008; Graham \& Reid, 2000; Van de Vliet et al., 2006; Zafeiridis et al., 2010). Yet, following a proper intervention program, people with ID have been shown to improve muscle strength and balance (Fotiadou et al., 2009).

Low performance on physical fitness measures by persons with ID is due to multiple factors: 1) natural characteristics like small stature (Graham \& Reid, 2000); 2) limited mental capacity and low attention levels (Vuijk, Hartman, Scherder, \& Visscher, 2010); 3) a sedentary way of life and minimum opportunities to participate in physical fitness programs (Bickum, 1995; Lotan et al., 2004; Pitetti \& Boneh, 1995); 4) lack of motivation for fitness training programs (Halle, Gabler-Halle, \& Chung, 1999); 5) lack of coordination and efficiency (Graham \& Reid, 2000); and 6) limitations and difficulties in motor development (Frey \& Chow, 2006; Hartman et al., 2010; Vuijk et al., 2010; Westendorp et al., 2011).

According to Merrick, Kandel, \& Morad (2003), many persons with severe and profound ID have been associated with medical problems and disease. In a review (Merrick, 2002) of mortality in this population in Israel for the period 1991-1997, $60 \%$ of 450 persons studied died before the age of 41 years, and for persons in the severe-profound group, this figure was $68 \%$. Cardiovascular problems accounted for $35 \%$ of these deaths, respiratory disease for $25 \%$, and infectious diseases for $9 \%$. People with ID have an increased prevalence of osteoporosis and increased fractures due to immobility, nutrition, and lack of activity (Center, Beange, \& McElduff, 1999). Given these threats to average life expectancy in this group, improving these individuals' physical fitness is of crucial importance. Failing to engage in physical activities may create many serious risks and dangers for people with ID, including muscle and bone injuries, development of diabetes type 2, obesity, hypertension and neuromuscular disorders (Vuori, 2004). These problems can be fatal, not only for people with ID but for people without disability (Draheim, 2006). Systematic participation in physical activities may benefit cardiorespiratory functioning and reduce such possible risks as high blood pressure and abnormal serum lipids, leading to reduced mortality rates (Lotan, Yalon-Chamovitz, \& Weiss, 2009).

Earlier studies reported beneficial effects of exercise for adults with ID, citing statistically significant reductions in weight (especially among those with mild ID) and BMI scores, and positive improvements in V-shape sit and reach tests and sit up tests (Wu et al., 2010). Benefits of physical activity were also observed in balance, strength, endurance and health self-perception (Carmeli et al., 2005). 
Improved physical fitness can promote a more active lifestyle, reduce health problems, and increase the likelihood of paid employment and non-institutionalized community living for individuals with ID (Chanias et al., 1998; Frey et al., 2008). Group exercising can help people with ID increase self-esteem and may be important paths for socialization and cooperation with other people sharing the same disability (Guidetti et al., 2010).

Performance on fitness evaluation tests has been shown to be influenced by such personal characteristics as gender, age and the level of ID (Pitetti, Yarmer, \& Fernhall, 2001; Skowronski et al., 2009). Unfortunately, however, there is little available information about physical fitness capacity or the use of various different fitness intervention training programs for adults with ID. In the ID literature there is a research gap with respect to what physical training intervention may be most beneficial and effective for significantly improving physical fitness with this population.

So far, most studies have shown improvement in balance and strength from non-standardized physical exercise interventions. Past research has suggested that sufficiently long intervention program duration is crucial for beneficial results. In most studies programs varied from 6 to 12 weeks in length (e.g., Borremans, Rintala, \& Kielinen, 2009 used a 12-week physical exercise program; Davis, Zhang, \& Hodson, 2011 used an 8-week adapted physical activity program; Giagazoglou et al., 2012 used a 10-week hippotherapy program; Giagazoglou et al., 2013 used a 12-week trampoline exercise intervention program; Rahmat \& Hasan, 2013 used a 6-week exercise program; Tsimaras \& Fotiadou, 2004 used a 12-week training program; and Wang et al., 2007 used a 12-week aquatic program), but this duration may not be enough to show effective and stable physical fitness improvement. In the context of this past literature, the present study sought to: 1) identify the initial physical fitness level of a group of adults with mild ID; and 2) evaluate the effects of a specific exercise training program, developed by Eurofit standardized measurements on these participants' physical fitness levels.

The basic hypothesis was that certain differences were between the 2 teams (experimental and control) on the variables measured after fitness training program.

\section{Method}

\subsection{Power Analysis}

The desired participant sample size for this study was estimated using $G^{*}$ power software (version 3.0) (Charan \& Biswas, 2013; Faul et al., 2007). We sought to detect a small to moderate interaction effect $(E t a 2=0.05)$ in a univariate repeated measure design ( $G^{*}$ Power: Statistical Power Analyses for Windows and Mac-Available in website http://www.gpower.hhu.de/). This analysis suggested that a sample size of 19 per group would be needed to achieve about $90 \%$ power at the 0.05 significance level. This sample size provided adequate statistical pow- 
er for analyzing fitness exercise effects with moderate to strong effect sizes in the areas of muscle strength, speed, balance and flexibility. Attrition rate of the sample has been thoroughly estimated and documented (Gustavson et al., 2012), and we recruited a total of 19 participants per group to account for potential attrition.

\subsection{Participants}

We recruited a convenience sample of thirty-eight adults $(\mathrm{N}=38 ; 10$ female and 28 male), with mild intellectual disabilities (MID) from September until January (16 weeks). They were attending a daily care and training centre of adults with disabilities in the southern region of Greece, named "K.E.E.P.E.A. HORIZONS". IQ scores extracted from the personal files of the participants, were used to classify the adults into MID groups (IQ scores= 55 - 70) according to the Diagnostic and Statistical Manual of Mental Disorder IV Text Revision (American Psychiatric Association, 2000). The age range of participants was 28 to 45 years and the IQ score range was $55 \pm 9$. The exclusion criteria of the study were adults with musculoskeletal and cardiorespiratory problems, adults with more than one disability, like spinal cord injury, cerebral palsy, sensory impairment, epileptic episodes, severe disorders of mental illness and autistic spectrum disorders, so that we can avoid possible complications or injuries.

Participants were equally divided into groups in accordance with their height, weight, BMI and mild intellectual level. They lived at home; they were not institutionalized and were members of the same training context. The intervention group ( $\mathrm{n}=19 ; 5$ females and 14 males) received an intensive 16-week exercise training program, whereas the control group ( $\mathrm{n}=19 ; 5$ females and 14 males) did not receive the intensive program.

The study was approved by the Laboratory of Adapted Physical Activity/Developmental and Physical Disabilities of the National and Kapodistrian University of Athens. Written informed consent was obtained from all parents' participants or their legal guardians after a detailed description of the research procedures was provided.

\subsection{Measures}

Before you begin to format your paper, first write and save the content as a separate text file. Keep your text and graphic files separate until after the text has been formatted and styled. Do not use hard tabs, and limit use of hard returns to only one return at the end of a paragraph. Do not add any kind of pagination anywhere in the paper. Do not number text heads-the template will do that for you.

Testing and Measurements. We evaluated participants' physical fitness with the Eurofit Physical Fitness Test Battery (Council of Europe, 1993). This standardized battery is a set of nine physical fitness tests including flexibility, speed, endurance and strength and easy to perform in field situations. This battery has 
good reliability and validity (Castro-Pinero et al., 2009; Castro-Pinero et al., 2010), and it has been widely used in the general population. Although its validity has not been specifically confirmed for use with individuals with ID (Van de Vliet et al., 2006), Mac Donncha, Watson, McSweeney, \& O’Donovan (1999) found adequate reliability of this battery when applied to individuals with mild ID or to individuals without ID. Also, anthropometric measurements, physical fitness and coordinative tests had a high reliability in people with ID (ICC range 0.90 - 0.99) (Berg \& Norman, 1996; Mac Donncha et al., 1999; Montgomery, Reid, \& Seidl, 1988). The test battery requires 35 - 40 minutes to administer, and it uses very simple equipment.

Assessment of static balance was performed using the Flamingo Balance Test. The task requires the participant to balance successfully on a single leg on a narrow-base beam 50 centimeters long, four centimeters high and three centimeters wide, coated with five millimeter thick non-slip material. The number of successful attempts to maintain balance for 60 seconds is recorded. Speed of hand movement was evaluated using the Plate Tapping Test. For this test, participants had to stand in front of a table on which there were two rubber disks 20 centimeters in diameter. The disks were 60 centimeters apart from each other. A rectangular plate was placed between them. Participants had to make 25 rapid single hand circles around the disks as fast as possible, moving their preferred hand right and left between the two disks. The non-preferred hand that was not used in the task had to be placed on the rectangular plate. The test was conducted two trials, and the researcher recorded the best score.

Flexibility was evaluated with the Sit and Reach Test. The participant was required to sit down and places his/her flanges against a box $(45 \times 35 \times 32 \mathrm{~cm})$ and reach as far in front as possible, with knees stretched. We conducted the test two times, and recorded the longest reach, defined by how far the fingertips were placed on a scale on top of the box.

Assessment of strength involved two components: 1) explosive leg strength was calculated from performance on the Standing Broad Jump Test; the participant performed a two-footed long jump twice, and we recorded the longest jump in centimeters; and 2) static hand strength was evaluated with the Handgrip Test; the participant held a dynamometer with his/her preferred hand and gripped its handle as hard as possible for two seconds, and we recorded results in kilograms from the best of two efforts.

Assessment of endurance was also evaluated with two tasks: 1) abdominal muscle endurance was assessed using the Sit-up Test requiring the participant to perform as many sit-ups as possible in 30 seconds, with one's knees at right angles and feet on the floor; we recorded the number of complete sit-ups performed within the stipulated time period, with a complete sit up cycle encompassing the period from starting position to sitting up and returning to the starting position; 2) Cardio-respiratory endurance was evaluated from the $10 \times 5$ meter Shuttle Run in which the participant was required to run five back and 
forth 10 meter distances as fast as possible; we recorded running time in seconds. The Tanita Body Fat Monitor (BC-545N model) and the Ultimate Scales (Tanita Corporation of America, Inc., Arlington Heights, IL) were used to measure body composition (fat and Visc fat). The Tanita BIA system provides a reliable and valid measurement and uses the variables of height, weight and impedance to determine body fat percentage in adults (2005). Measurement included scales for valid numbers and to avoid miscalculations. Tanita uses leg-to-leg bioelectrical impedance analysis (BIA, 1996) which is a relatively simple, quick (takes only a few minutes), quick and non-invasive technique, with minimal intra- and inter-observer variability (Ritchie, Miller, \& Smiciklas-Wright, 2005).

\subsection{Procedure}

We employed a quasi-experimental nonequivalent-control-group design (Pre-testIntervention-Post-test) in this study, deemed to be particularly appropriate in educational research (Thomas, Nelson, \& Silverman, 2005). First, in the pre-test period all participants were evaluated with Eurofit Physical Fitness Test Battery (7 subtests) in order to identify their physical fitness levels in four areas: balance skills, strength, endurance and speed. Participants were randomly divided into two groups. Groups were randomly assigned to either the Intervention or Control group.

The Intervention Group received an intensive 16-week exercise training program, whereas the Control Group received no training program and were simply asked to continue their physical activity as usual. The exercise intervention program was performed two days a week, for four consecutive months. The two training sessions each week were 60 -minutes each and were comprised of a variety of motor activities designed to target speed, muscle strength, balance, coordination and endurance. Tests were conducted either at the courtyard or gym of the daily care and training center which offered all facility requirements (health and sanitary requirements, adequate space, lighting, proper flooring, sufficient equipment and accessories, measuring instruments). There were no session drop-outs, though some participants needed encouragement to continue the tasks. The physical education teachers were responsible for each training session, and the investigator was always present for interventions offered.

\subsection{Exercise Training Program}

The training sessions was developed based on seven (7) standardized Eurofit motor tests taking into account the Eurofit pre-test research results. Particular characteristics of individuals with intellectual disabilities also were considered. Then, a 16-week standardized training exercise protocol was decided upon and developed by the researchers, based on the expected progression of training from initial to improvement stages after the implementation of the intervention program. The training program included two training sessions per week (60 minutes per session), each consisting of warm-up, flexibility, strength, stability 
training, and cardio and cool down. The exercises were divided into three parts (12 sections), as shown in Table 1.

The 60-minutes training sessions were targeted to improve speed, muscle strength, balance, coordination and endurance of the participants, and they emphasized upper and lower limbs muscles, trunk, shoulders, elbows, wrists, fingers, abdominal muscles, hip and knees. Two physical education teachers were trained to deliver the intervention protocol before implementing the study.

\subsection{Statistical Analysis}

All data analyses were performed with version 21.0 of the Statistical Package for Social Sciences (SPSS), and statistical significance for group comparisons was set at $p<0.05$ (Norusis, 2012). The study was a two-group randomized controlled trial with repeated measures using gender as a stratifying factor. First, descriptive statistics (means, standard deviations, range) were calculated for all participants $(n=38)$ on all variables. Second, repeated measures analysis of variance (RMANOVA) was used to examine the participants' pre- and post-training measurements. Lastly, discriminant function analysis was used: 1) to determine which variables significantly dissociated the two groups; and 2) to determine the number of participants that classified at each level of physical fitness on the tested variables. All variables were tested for statistically significant group-by-time interactions.

\section{Results}

As noted above, there was no subject attrition from the intervention, possibly due to the relatively short-term program (4 months exercise training). Means and standard deviations for all anthropometric characteristics (weight, fat, visc

Table 1. The exercise training program.

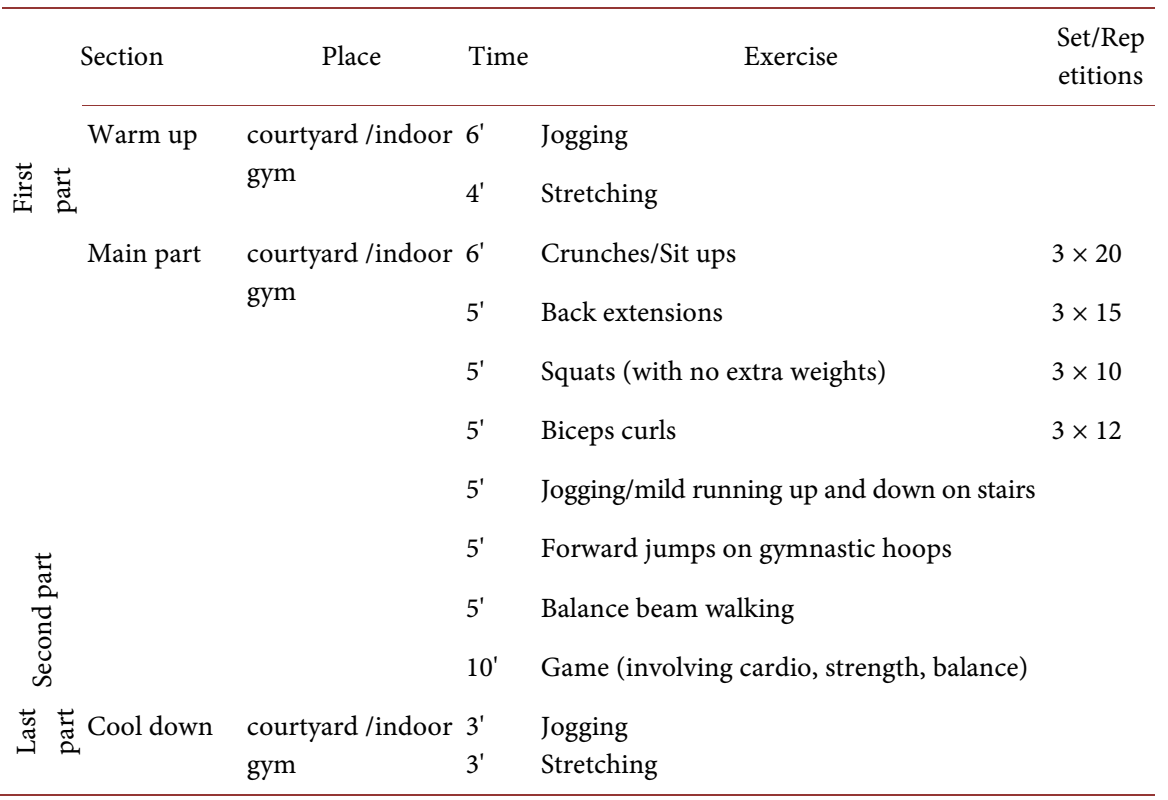


fat, BMI) and other participants' descriptive characteristics of are shown in Table 2. The results show that the mean anthropometric characteristics suggestive of better health and all physical fitness measures for the intervention group were reflected positive improvements at post-tests (after intervention).

The results of RMANOVA showed that the two groups were significantly different on specific tests both before and after intervention. Initially, RMANOVA $(p<0.05)$ showed that the major effect of the intervention were statistically significant-Wilks' $\mathrm{L}=0.040, \mathrm{~F}=(22.8)=8.63, p<0.002, \eta^{2}=0.960$ - and the main effects of the subtests were statistically significant for each measure. Subsequent comparisons showed that the largest differences $(p<0.05)$ in performance between two groups after the intervention program were recorded in the following subtests: 1) Plate Tapping Test2, 2) Sit-up Test2, 3) Standing Broad Jump Test2, 4) Sit and Reach Test2, 5) Shuttle Run2. The results of RMANOVA for two groups (intervention and control) are shown in Table 3.

Statistically, significant group-by-time interactions were observed in five out of seven fitness tests measured, meaning that these changes were different between groups across time. The positive intervention effects were seen in: 1) Plate Tapping Test $2[\mathrm{~F}(1,29)=6.36, p=0.017], 2)$ Sit-up Test $2[\mathrm{~F}(1,29)=3.39, p=$ $0.046], 3)$ Standing Broad Jump Test2 $[\mathrm{F}(1,29)=10.30, p=0.003]$, 4) Sit and Reach Test2 $[\mathrm{F}(1,29)=22.24, p=0.000], 5)$ Shuttle Run2 $[\mathrm{F}(1,29)=13.14, p=$ 0.001]. Following 16 weeks of training, the participants' fitness level on the above distinct measures changed respectively.

Then, discriminant analysis of variance was applied to determine: 1) the variables significantly separating the two groups; and 2) the number of participants, categorized properly (correctly classified) to the level of fitness (fitness or not) according to the variables measured after intervention exercise training program.

Table 2. Descriptive characteristics pre and post-exercise training program.

\begin{tabular}{ccccccc}
\hline \multirow{2}{*}{ Variables } & \multicolumn{2}{c}{ Intervention group $(\mathrm{N}=19)$} & \multicolumn{2}{c}{ Control group $(\mathrm{N}=19)$} & \multicolumn{2}{c}{ Group $\times$ time interaction effects } \\
\cline { 2 - 7 } & Pre & Post (weeks 16) & Pre & Post (weeks 16) & F & p.Value \\
\hline Weight (Kg) & $78.6 \pm 15.98$ & $75.88 \pm 15.61$ & $77.58 \pm 13.09$ & $76.83 \pm 12.8$ & 0.03 & 0.861 \\
Fat & $40.31 \pm 13.53$ & $37.91 \pm 13.62$ & $40.25 \pm 11.04$ & $39.11 \pm 10.23$ & 0.06 & 0.795 \\
Visc Fat & $9.52 \pm 3.25$ & $8.52 \pm 2.8$ & $9.83 \pm 4.19$ & $9.25 \pm 4.09$ & 0.34 & 0.562 \\
BMI & $31.41 \pm 6.09$ & $29.5 \pm 5.65$ & $31.03 \pm 5.42$ & $30.46 \pm 5.75$ & 0.05 & 0.810 \\
Flamingo Balance Test & $8.21 \pm 3.9$ & $6.37 \pm 3.74$ & $7.25 \pm 3.98$ & $7.25 \pm 3.79$ & 0.40 & 0.530 \\
Plate Tapping Test & $442.5 \pm 112.72$ & $396.47 \pm 103.51$ & $364.47 \pm 103.29$ & $366.91 \pm 106.53$ & $60.36^{*}$ & 0.017 \\
Sit-Up Test & $11.79 \pm 5.77$ & $15.31 \pm 5.47$ & $10.33 \pm 8.09$ & $10.50 \pm 9.14$ & $3.39^{*}$ & 0.046 \\
Standing Broad Jump Test & $47.68 \pm 33.77$ & $73.21 \pm 40.71$ & $41.75 \pm 34.62$ & $46.00 \pm 38.48$ & $10.30^{* *}$ & 0.003 \\
Sit and Reach Test & $13.58 \pm 3.87$ & $18.16 \pm 4.76$ & $7.25 \pm 4.99$ & $8.75 \pm 6.32$ & $22.24^{* *}$ & 0.000 \\
Shuttle Run & $353.58 \pm 61.83$ & $295.52 \pm 58.83$ & $416.91 \pm 92.00$ & $393.50 \pm 92.15$ & $13.14^{* *}$ & 0.001 \\
Handgrip Test & $19.24 \pm 8.19$ & $22.35 \pm 10.44$ & $16.20 \pm 5.66$ & $17.12 \pm 5.61$ & 2.52 & 0.123 \\
\hline
\end{tabular}

FM, body fat; BMI, body mass index; d.f. $(1,29)$; fs, for all variables were tested for group-by-time interactions; ${ }^{\star} p<0.05$ Post vs. Pre; ${ }^{\star *} p<0.01$ Post vs. Pre. 
The results showed that three subtests "Sit and Reach Test2" (intervention group $M=18.16$ /control group $M=8.75$ ), “Shuttle Run2" (intervention group $M=295.53 /$ control group $M=393.5$ ) and "Standing Broad Jump Test2" (intervention group $M=93.21 /$ control group $M=46.00$ ) significantly distinguished the two groups. The normal correlation coefficient (canonical correlation coefficient) was $0.83,-0.70$ and 0.07 , respectively, indicating that these variables explained $83.9 \%$ of the total dispersion (percentage of correct classification based on three subtests). The overall results of discriminant analysis of variance are shown in Table 4.

Table 3. RMANOVA results pre and post-exercise training program.

\begin{tabular}{cccc}
\hline Variables & F & $p$ & Eta Squared \\
\hline Plate Tapping Test1 & 1.358 & 0.253 & 0.045 \\
Plate Tapping Test2 & $6.361^{*}$ & $\mathbf{0 . 0 1 7}$ & 0.180 \\
Sit-Up Test1 & 0.342 & 0.563 & 0.012 \\
Sit-Up Test2 & $3.390^{*}$ & $\mathbf{0 . 0 4 6}$ & $\mathbf{0 . 1 0 5}$ \\
Standing Broad Jump Test1 & 5.777 & 0.023 & 0.166 \\
Standing Broad Jump Test2 & $\mathbf{1 0 . 3 0 6 ^ { * * }}$ & $\mathbf{0 . 0 0 3}$ & $\mathbf{0 . 2 6 2}$ \\
Sit and Reach Test1 & 15.679 & 0.000 & 0.351 \\
Sit and Reach Test2 & $\mathbf{2 2 . 2 4 1 ^ { * * }}$ & $\mathbf{0 . 0 0 0}$ & $\mathbf{0 . 4 3 4}$ \\
Shuttle Run1 & 5.284 & 0.059 & 0.154 \\
Shuttle Run2 & $\mathbf{1 3 . 1 4 8 ^ { * * }}$ & $\mathbf{0 . 0 0 1}$ & $\mathbf{0 . 3 1 2}$
\end{tabular}

${ }^{\star} p<0.05 ;{ }^{* *} p<0.01$.

Table 4. Results of discriminant analysis of variance according to category (intervention and control group).

\begin{tabular}{|c|c|c|c|c|c|}
\hline Variables & Wilks' Lambda & $\begin{array}{c}\text { Standardized } \\
\text { Coefficient }\end{array}$ & $\begin{array}{l}\text { Unstandardized } \\
\text { Coefficient }\end{array}$ & $p$ & $\begin{array}{l}\text { Canonical } \\
\text { Correlation }\end{array}$ \\
\hline \multicolumn{6}{|c|}{ Sit and Reach Test2 } \\
\hline \multirow[t]{2}{*}{ Category } & & & & & 0.83 \\
\hline & $0.56^{\star *}$ & 0.83 & $\begin{array}{c}0.15 \\
\text { Constant }-0.72\end{array}$ & 0.000 & \\
\hline \multicolumn{6}{|l|}{ Shuttle Run2 } \\
\hline \multirow[t]{2}{*}{ Category } & & & & & -0.70 \\
\hline & $0.69^{* *}$ & -0.70 & $\begin{array}{c}-0.01 \\
\text { Constant }-0.72\end{array}$ & 0.001 & \\
\hline \multicolumn{6}{|c|}{ Standing Broad Jump Test2 } \\
\hline \multirow[t]{2}{*}{ Category } & & & & & 0.07 \\
\hline & $0.74^{* *}$ & 0.55 & $\begin{array}{c}0.00 \\
\text { Constant }-0.72\end{array}$ & 0.003 & \\
\hline
\end{tabular}

${ }^{\star} p<0.05 ;{ }^{* *} p<0.01$. 
Also, there was an indication of statistically significant differences between genders. MANOVA showed a significant effect of gender on the dependent variables of the research (Wilks' $\mathrm{L}=0.001, \mathrm{~F}=(17.1)=62.41$, $\mathrm{df}=17, p=0.008<$ $\left.0.05, \eta^{2}=0.999\right)$. Discriminant analysis of variance showed that women benefited more than men from their participation in the intervention program mainly on two anthropometric characteristics weight $2(p=0.003)$ and fat $2(p=$ 0.001). The results of the analysis by gender are shown in Table 5 .

\section{Discussion}

After the text edit has been completed, the paper is ready for the template. Duplicate the template file by using the Save As command, and use the naming convention prescribed by your journal for the name of your paper. In this newly created file, highlight all of the contents and import your prepared text file. You are now ready to style your paper.

The study investigated: 1) the differences between two groups of adults with mild ID (intervention and control) through pre and post exercise intervention program; and 2) the variables could distinguish significantly the two groups after intervention program. As it was expected, higher levels of physical fitness and some improvement on anthropometry characteristics observed in the intervention group after completed the 4 months training.

Statistical analysis showed significant improvement on anthropometry characteristics on all individuals that participated in intervention program, specifically, on weight, fat and BMI. Also, data showed that intervention group improved their fitness levels significantly on the following five tests: "Plate Tapping Test", "Sit and Reach Test", "Standing Broad Jump Test", "Sit-up Test", and "Shuttle Run". Further analysis showed that "sit up test" was the most significant variable that substantially separated the two groups (intervention and control group). Results were also statistically significant according to the effect of gender; specifically, women benefited more than men on weight and fat loss.

Our results agree with the findings of previous studies in adults with mild ID indicated that structural physical training program had positive effects on muscle

Table 5. Results of discriminant analysis of variance according to anthropometric characteristics by gender.

\begin{tabular}{cccccc}
\hline Variables & Wilks' Lambda & $\begin{array}{c}\text { Standardized } \\
\text { Coefficient }\end{array}$ & $\begin{array}{c}\text { Unstandardized } \\
\text { Coefficient }\end{array}$ & $p$ & $\begin{array}{c}\text { Canonical } \\
\text { Correlation }\end{array}$ \\
\hline Gender & & & & 0.79 \\
Weight2 & $0.476^{* *}$ & -0.97 & -0.06 & 0.003 & 0.68 \\
Fat2 & & & & \\
& $0.363^{* *}$ & -20.98 & -0.24 & 0.001 & \\
& & & Constant -1.019 & \\
\hline
\end{tabular}

${ }^{\star} p<0.05 ;{ }^{* *} p<0.01$. 
strength (sit up test and jump test) and aerobic endurance (shuttle run) (Golubovic et al., 2012). Also, Tsimaras \& Fotiadou's study (2004) found the dynamic balance ability and muscle strength of the participants with ID were significantly improved. Graham \& Reid (2000) observed improvement on muscle strength by their trainees. Improvement of muscle endurance and strength have crucial importance for individuals with ID, which they follow a sedentary life (Bickum, 1995; Graham \& Reid, 2000; Lotan et al., 2004; Pitetti \& Boneh, 1995). Giagazoglou et al. (2013) after intervention program on trampoline supported that their trainees improved strength, flexibility and neuromuscular coordination. This improvement could be due to the interest that this type of exercise caused to individuals with ID.

According to the literature, previous studies have shown that individuals with ID face difficulties on movement coordination from childhood to adulthood (Guidetti et al., 2010). These difficulties on movement coordination justifies the low performance on balance tests (Hale, Bray, \& Littmann, 2007; Minshew, Sung, Jones, \& Furman, 2004). Our findings supported the motor coordination difficulties showing significantly low performance of adults with ID on "Plate Tapping Test" as well as "Standing Broad Jump Test".

The duration of an intervention training program has crucial importance for results. A 6-months intervention program of adults with mild ID has a better perception of well-being, as well as balance and strength improvement (Carmeli et al., 2005). In our study the minimum weight loss that observed may be due to intervention program's limited time. Similar result has been found in other studies (Fragala et al., 2005; Ozmen et al., 2007; Wu et al., 2010).

The present results support the selection of appropriate and task-specific standardized exercises which can improve specific physical skills and fitness levels of individuals with ID. The development of Adapted Physical Activity programs tailored to individual needs is necessary in the daily care and training centers of adults with disabilities, with the aim of promoting an active lifestyle. According to our research findings, we recommend a specialized training program for people with mild ID that improves muscle strength, aerobic endurance, weight loss and muscle endurance for more than 4 months (16 weeks) to see if there will be an even more improvement and advantages.

\section{Limitations}

The limitations of the present study concern the small number of our sample and also the difficulties to control all factors that could affect the training procedure such as, motivation, interest in participation and health condition. For all these reasons, it is needed further investigation. It's easy to assume that a more playful exercise program would get their interest to participate and finally to be a way of life for these people. Also, in the present study participated only adults with ID. However, there are many other syndromes accompanied by ID, like DS (Down syndrome) with large differences in the pathophysiological characteris- 
tics, so it's not possible to generalize the findings of our study for these accompanied syndromes.

Another limitation was the difficulty to minimize the outdoor activities of the participants. However, the data on the Table 2 present about whether the intervention and control group were different before the intervention. Obviously, the intervention group was not already more athletic than the control group.

The last limitation was the diet followed by each participant. Each participant had their own everyday intake in calories without any restriction of what they have to eat. With the intervention program we wanted to see better results on anthropometry characteristics such as weight loss, fat loss and improvement of BMI but with this factor the outcome was not the expected.

\section{Conclusion}

In conclusion, the present study showed improvements in muscle strength and endurance, balance, flexibility, speed and cardio-respiratory endurance as well as in anthropometry characteristics, such as weight, fat and BMI by adults with mild ID who participated in a four-month (16-week) standardized intervention physical exercise program.

This provides evidence that a standardized physical exercise and specific training program can be an effective intervention for improving fitness levels of adults with mild ID. So, individuals with ID could be more active in order to participate in outdoor activities of their community, promoting their integration with people without disabilities, improving their physical fitness levels they can deal with everyday activities with greater ease, and following a well-being and healthier way of life.

\section{Acknowledgements}

We would like to thank all the adults with intellectual disabilities as well the adapted physical education teacher that contributed to conduct this study. We would also like to thank the director of the daily care and training centre titled K.E.E.P.E.A. HORIZONS who gave us the permission to use the center's facilities.

\section{Conflicts of Interest}

The authors declare no conflicts of interest regarding the publication of this paper.

\section{References}

American Psychiatric Association (2000). Diagnostic and Statistical Manual of Mental Disorders (4th ed.). Washington DC: American Psychiatric Association.

Berg, K., \& Norman, K. E. (1996). Functional Assessment of Balance and Gait. Clinics in Geriatric Medicine, 12, 705-723. https://doi.org/10.1016/S0749-0690(18)30197-6

BIA (1996). Bioelectrical Impedance Analysis (BIA) in Body Composition Measurement: 
National Institutes of Health Technology Assessment Conference Statement. American Journal of Clinical Nutrition, 64, 524-532. https://doi.org/10.1093/ajcn/64.3.524S

Bickum, D. (1995). The History of Graded Exercise Testing in Cardiac Rehabilitation. Oregon: Microform Publication.

Borremans, E., Rintala, P., \& Kielinen, M. (2009). Effectiveness of an Exercise Training Program on Youth with Asperger Syndrome. European Journal of Adapted Physical Activity, 2, 15-25.

Carmeli, E., Bar-Yossef, T., Ariav, C., Levy, R., \& Lieberman, D. G. (2008). Perceptual-Motor Coordination with Mild Intellectual Disability. Disability and Rehabilitation, 30, 323-329. https://doi.org/10.1080/09638280701265398

Carmeli, E., Zinger, T., Morad, M., \& Merrick, J. (2005). Can Physical Training Have an Effect on Well-Being in Adults with Mild Intellectual Disability? Mechanisms of Aging and Development, 126, 299-304. https://doi.org/10.1016/j.mad.2004.08.021

Castro-Pinero, J., Artero, E. G., Espana-Romero, V., Ortega, F. B., Sjostrom, M., Suni, J., \& Ruiz, J. R. (2010). Criterion-Related Validity of Field-Based Fitness Tests in Youth: A Systematic Review. British Journal of Sports Medicine, 44, 934-943.

https://doi.org/10.1136/bjsm.2009.058321

Castro-Pinero, J., Chillon, P., Ortega, F. B., Montesinos, J. L., Sjostrom, M., \& Ruiz, J. R. (2009). Criterion-Related Validity of Sit-and-Reach and Modified Sit-and-Reach Test for Estimating Hamstring Flexibility in Children and Adolescents Aged 6 - 17 Years. International Journal of Sports Medicine, 30, 658-662.

https://doi.org/10.1055/s-0029-1224175

Center, J., Beange, H., \& McElduff, A. (1999). People with Mental Retardation Have an Increased Prevalence of Osteoporosis: A Population Study. American Journal on Mental Retardation, 103, 19-28. https://doi.org/10.1352/0895-8017(1998)103<0019:PWMRHA>2.0.CO;2

Chanias, A. K., Reid, G., \& Hoover, M. L. (1998). Exercise Effects on Health-Related Physical Fitness of Individuals with an Intellectual Disability: A Meta-Analysis. Adapted Physical Activity Quarterly, 15, 119-140. https://doi.org/10.1123/apaq.15.2.119

Charan, J., \& Biswas, T. (2013). How to Calculate Sample Size for Different Study Designs in Medical Research? Indian Journal of Psychological Medicine, 35, 121-126. https://doi.org/10.4103/0253-7176.116232

Council of Europe, Committee for the Development of Sport (1993). EUROFIT: Handbook for the EUROFIT Tests of Physical Fitness. Strasbourg: Council of Europe.

Davis, K., Zhang, G., \& Hodson, P. (2011). Promoting Health-Related Fitness for Elementary Students with Intellectual Disabilities through a Specifically Designed Activity Program. Journal of Policy and Practice in Intellectual Disabilities, 8, 77-84. https://doi.org/10.1111/j.1741-1130.2011.00293.x

Draheim, C. (2006). Cardiovascular Disease Prevalence and Risk Factors of Persons with Mental Retardation. Mental Retardation and Developmental Disabilities Research Reviews, 12, 3-12. https://doi.org/10.1002/mrdd.20095

Faul, F., Erdfelder, E., Lang, A.-G., \& Buchner, A. (2007). GPower 3: A Flexible Statistical Power Analysis Program for the Social, Behavioral, and Biomedical Sciences. Behavior Research Methods, 39, 175-191. https://doi.org/10.3758/BF03193146

Fotiadou, E. G., Neofotistou, K. H., Sidiropoulou, M. P., Tsimaras, V. K., Mandroukas, A. K., \& Angelopoulou, N. A. (2009). The Effect of a Rhythmic Gymnastics Program on the Dynamic Balance Ability of Individuals with Intellectual Disability. Journal of 
Strength and Conditioning Research, 23, 2102-2106.

https://doi.org/10.1519/JSC.0b013e3181b8d3b5

Fragala, M., Haley, S., Rabin, J., \& Kharasch, V. (2005). A Fitness Program for Children with Disabilities. Physical Therapy, 85, 1182-1200.

Frey, G., \& Chow, B. (2006). Relationship between BMI, Physical Fitness and Motor Skills in Youth with mild Intellectual Disabilities. International Journal of Obesity, 30, 861-867. https://doi.org/10.1038/sj.ijo.0803196

Frey, G., Stanish, H., \& Temple, V. (2008). Physical Activity of Youth with Intellectual Disability. Review and Research Agenda, 25, 95-117.

Giagazoglou, P., Arabatzi, F., Dipla, K. et al. (2012). Effect of a Hippotherapy Intervention Program on Static Balance and Strength in Adolescents with Intellectual Disabilities. Research in Developmental Disabilities, 33, 2265-2270.

https://doi.org/10.1016/j.ridd.2012.07.004

Giagazoglou, P., Kokaridas, D., Sidiropoulou, M., Patsiaouras, A., Karra, C., \& Neofotistou, K. (2013). Effects of a Trampoline Exercise Intervention on Motor Performance and Balance Ability of Children with Intellectual Disabilities. Research in Developmental Disabilities, 34, 2701-2707. https://doi.org/10.1016/j.ridd.2013.05.034

Golubovic, S., Maksimovic, J., Golubovic, B., \& Glumbic, N. (2012). Effects of Exercise on Physical Fitness in Children with Intellectual Disability. Research in Developmental Disabilities, 33, 608-614. https://doi.org/10.1016/j.ridd.2011.11.003

Graham, A., \& Reid, G. (2000). Physical Fitness of Adults with an Intellectual Disability: A 13-Year Follow-Up Study. Research Quarterly for Exercise and Sport, 71, 152-161. https://doi.org/10.1080/02701367.2000.10608893

Guidetti, L., Franciosi, E., Gallotta, M., Emerenziani, G., \& Baldari, C. (2010). Could Sport Specialization Influence Fitness and Health of Adults with Mental Retardation? Research in Developmental Disabilities, 31, 1070-1075.

https://doi.org/10.1016/j.ridd.2010.04.002

Gustavson, K., von Soest, T., Karevold, E., \& Røysamb, E. (2012). Attrition and Generalizability in Longitudinal Studies: Findings from a 15-Year Population-Based Study and a Monte Carlo Simulation Study. BMC Public Health, 12, 918.

https://doi.org/10.1186/1471-2458-12-918

Hale, L., Bray, A., \& Littmann, A. (2007). Assessing the Balance Capabilities of People with Profound Intellectual Disabilities Who Have Experienced a Fall. Journal of Intellectual Disability Research, 51, 260-268. https://doi.org/10.1111/j.1365-2788.2006.00873.x

Halle, J. W., Gabler-Halle, D., \& Chung, Y. B. (1999). Effects on a Peer Mediated Aerobic Conditioning Program on Fitness Levels of Youth with Mental Retardation: Two Systematic Replications. Mental Retardation, 37, 435-448. https://doi.org/10.1352/0047-6765(1999)037<0435:EOAPAC>2.0.CO;2

Hartman, E., Houwen, S, Scherder, E., \& Visscher, C. (2010). On the Relationship between Motor Performance and Executive Functioning in Children with Intellectual Disabilities. Journal of Intellectual Disability Research, 54, 468-477. https://doi.org/10.1111/j.1365-2788.2010.01284.x

Lotan, M., Isakov, E., Kessel, S., \& Merrick, J. (2004). Physical Fitness and Functional Ability of Children with Intellectual Disability: Effects of a Short-Term Daily Treadmill Intervention. The Science World Journal, 4, 449-457.

https://doi.org/10.1100/tsw.2004.97

Lotan, M., Yalon-Chamovitz, S., \& Weiss, P. (2009). Improving Physical Fitness of Individuals with Intellectual and Developmental Disability through a Virtual Reality Inter- 
vention Program. Research in Developmental Disabilities, 30, 229-239. https://doi.org/10.1016/j.ridd.2008.03.005

Mac Donncha, C., Watson, A., McSweeney, T., \& O’Donovan, D. (1999). Reliability of Eurofit Physical Fitness Items for Adolescent Males with and without Mental Retardation. Adapted Physical Activity Quarterly, 16, 86-95. https://doi.org/10.1123/apaq.16.1.86

Merrick, J. (2002). Mortality of Persons with Intellectual Disability in Residential Care in Israel 1991-1997. Journal of Intellectual and Developmental Disability, 27, 265-272. https://doi.org/10.1080/1366825021000029320

Merrick, J., Kandel, I., \& Morad, M. (2003) Health Needs of Adults with Intellectual Disability Relevant for the Family Physician. The Scientific World Journal, 3, 937-945. https://doi.org/10.1100/tsw.2003.91

Minshew, N. J., Sung, K., Jones, B. L., \& Furman, J. M. (2004). Underdevelopment of the Postural Control System in Autism. Neurology, 63, 2056-2061. https://doi.org/10.1212/01.WNL.0000145771.98657.62

Montgomery, D. L., Reid, G., \& Seidl, C. (1988). The Effects of Two Physical Fitness Programs Designed for Mentally Retarded Adults. Canadian Journal of Sport Sciences, 13, 73-78.

Norusis, M. (2012). IBM SPSS Statistics 21 Guide to Data Analysis. Pearson: SPSS Inc.

Ozmen, T., Ryildirim, N. U., Yuktasir, B., \& Beets, M. W. (2007). Effects of School-Based Cardiovascular-Fitness Training in Children with Mental Retardation. Pediatric Exercise Science, 19, 171-178. https://doi.org/10.1123/pes.19.2.171

Pitetti, K. H., Yarmer, D. A., \& Fernhall, B. (2001). Cardiovascular Fitness and Body Composition of Youth with and without Mental Retardation. Adapted Physical Activity Quarterly, 18, 127-141. https://doi.org/10.1123/apaq.18.2.127

Pitetti, K., \& Boneh, S. (1995). Cardiovascular Fitness as Related to Leg Strength in Adults with Mental Retardation. Medicine and Science in Sports and Exercise, 27, 423-428. https://doi.org/10.1249/00005768-199503000-00020

Rahmat, A., \& Hasan, D. (2013). The Effect of Core Stabilization Exercises on Factors Physical Fitness to Mental Retardation. Medicina Sportiva, 9, 2058-2062.

Ritchie, J. D., Miller, C. K., \& Smiciklas-Wright, H. (2005). Tanita Foot-to-Foot Bioelectrical Impedance Analysis System Validated in Older Adults. Journal of American Dietetic Association, 105, 1617-1619. https://doi.org/10.1016/j.jada.2005.07.011

Skowronski, W., Horvat, M., Nocera, J., Roswal, G., \& Croce, R. (2009). Eurofit Special: European Fitness Battery Score Variation among Individuals with Intellectual Disabilities. Adapted Physical Activity Quarterly, 26, 54-67. https://doi.org/10.1123/apaq.26.1.54

Thomas, J. R., Nelson, J. K., \& Silverman, J. (2005). Research Methods in Physical Activity (5th ed.). Champaign, IL: Human Kinetics.

Tsimaras, V., \& Fotiadou, E. (2004). Effect of Training on the Muscle Strength and Dynamic Balance Ability of Adults with Down Syndrome. Journal of Strength and Conditioning Research, 18, 343-347.

Van de Vliet, P., Rintala, P., Frojd, K., Verellen, J., Van Houtte, S., Daly, D., \& Vanlandewijck, Y. (2006). Physical Fitness Profile of Elite Athletes with Intellectual Disability. Scandinavian Journal of Medicine and Science in Sports, 16, 417-425. https://doi.org/10.1111/j.1600-0838.2006.00539.x

Vuijk, P., Hartman, E., Scherder, E., \& Visscher, C. (2010). Motor Performance of Children with Mild Intellectual Disability and Borderline Intellectual Functioning. Journal of 
Intellectual Disability Research, 54, 955-965.

https://doi.org/10.1111/j.1365-2788.2010.01318.x

Vuori, I. (2004). Physical Inactivity Is a Cause and Physical Activity Is a Remedy for Major Public Health Problems. Kinesiology, 36, 123-153.

Wang, T.-J., Belza, B., Thompson, F. E., Whitney, J. D., \& Bennett, K. (2007). Effects of Aquatic Exercise on Flexibility, Strength and Aerobic Fitness in Adults with Osteoarthritis of the Hip or Knee. Journal of Advanced Nursing, 57, 141-152.

https://doi.org/10.1111/j.1365-2648.2006.04102.x

Westendorp, M., Hartman, E., Houwen, S., Smith, J., \& Visscher, C. (2011). The Relationship between Gross Motor Skills and Academic Achievement in Children with Learning Disabilities. Research in Developmental Disabilities, 32, 2773-2779.

https://doi.org/10.1016/j.ridd.2011.05.032

Wu, C., Lin, J., Hu, J., Yen, C., Yen Cheng, T., Chou, Y., \& Wu, P. (2010). The Effectiveness of Healthy Physical Fitness Programs on People with Intellectual Disabilities Living in a Disability Institution: Six-Month Short-Term Effect. Research in Developmental Disabilities, 31, 713-717. https://doi.org/10.1016/j.ridd.2010.01.013

Zafeiridis, A., Giagazoglou, P., Dipla, K., Salonikidis, K., Karra, C., \& Kellis, E. (2010). Muscle Fatigue during Intermittent Exercise in Individuals with Mental Retardation. Research in Developmental Disabilities, 31, 388-396.

https://doi.org/10.1016/j.ridd.2009.10.003 